\title{
Effect of Therapeutic Dose of Indomethacin on the Cerebral Circulation of Newborn Pigs
}

\author{
CHARLES W. LEFFLER, DAVID W. BUSIJA, AND DONATHAN G. BEASLEY
}

Department of Physiology and Biophysics, University of Tennessee, Memphis, Tennessee 38163

\begin{abstract}
The effects of treatment with $0.2 \mathrm{mg} / \mathrm{kg}$ of indomethacin on the cerebral blood flow and cerebral oxygen consumption of hypotensive, unanesthetized, newborn pigs were investigated. Hypotension was induced by hemorrhage $(30 \mathrm{ml} / \mathrm{kg})$ which reduced mean arterial pressure from 60 to $34 \mathrm{~mm} \mathrm{Hg}$. The decline in cerebral vascular resistance that occurred with hemorrhage allowed blood flow to all brain regions and cerebral oxygen consumption to continue unchanged. Treatment with $0.2 \mathrm{mg}$ of indomethacin decreased plasma 6-keto-prostaglandin $F_{1 \alpha}$ markedly and caused a modest increase in cerebral vascular resistance from $0.75 \pm 0.07$ to $0.85 \pm 0.02 \mathrm{~mm} \mathrm{Hg} \cdot 100$ $\mathrm{g} \cdot \mathrm{min} / \mathrm{ml}$ at $40 \mathrm{~min}$ posttreatment. As a result, blood flow throughout the brain fell about $20 \%$. Similarly, cerebral oxygen consumption declined from $2.88 \pm 0.13$ to $2.03 \pm$ $0.21 \mathrm{ml} \mathrm{O} / 100 \mathrm{~g} \cdot \mathrm{min}$ following treatment of hypotensive piglets with $0.2 \mathrm{mg} / \mathrm{kg}$ of indomethacin. However, all piglets were conscious $\mathbf{4 0} \mathrm{min}$ after treatment. We conclude that, although $0.2 \mathrm{mg} / \mathrm{kg}$ of indomethacin affects cerebral hemodynamics of hypotensive piglets, the effects are very modest in comparison to large increases in cerebral vascular resistance, decreases in cerebral blood flow and oxygen consumption, and coma that follow treatment of hypotensive piglets with $5 \mathrm{mg} / \mathrm{kg}$ of indomethacin. (Pediatr Res 21: 188-192, 1987)
\end{abstract}

Abbreviation

PG, prostaglandin

We have obtained evidence that is consistent with the hypothesis that prostanoids are important in regulation of cerebral hemodynamics in the neonate $(1-5)$. Cerebral blood flow and cerebral oxygen consumption in unanesthetized newborn pigs were maintained constant at arterial pressures as low as $35 \mathrm{~mm}$ $\mathrm{Hg}$ (5). Treatment of hypotensive newborn pigs with a dose of indomethacin $(5 \mathrm{mg} / \mathrm{kg})$ sufficient to inhibit cerebral prostanoid synthesis and decrease vascular prostanoids to nondetectable levels increased cerebral vascular resistance, decreased cerebral blood flow and cerebral oxygen consumption, and produced coma in $75 \%$ of the piglets so treated (5).

Treatment of premature newborn infants with a much lower dose of indomethacin $(0.2+0.1 \mathrm{mg} / \mathrm{kg} 12 \mathrm{~h})$ routinely is employed to close a patent ductus arteriosis. Further, recent evidence suggests that treatment of premature newborns at birth

Received July 11, 1986; accepted October 1, 1986.

Correspondence Dr. C. W. Leffler, Department of Physiology and Biophysics, 894 Union Ave (NA 426), Memphis, TN 38163.

The research was supported in part by grants-in-aid from the National Institutes of Health and the Tennessee Affiliate of the American Heart Association and by a program project grant from the National Institutes of Health. C.W.L. is an Established Investigator of the American Heart Association. and shortly thereafter with a low dose of indomethacin may decrease the incidence and/or severity of intraventricular/periventricular hemorrhage $(6,7)$. Since severe hypotension is common in very premature infants, the possibility that indomethacin could cause a severe decrease in cerebral blood flow in hypotensive newborns must be considered.

Therefore, the present study was undertaken to determine the effects of the dose of indomethacin used therapeutically in newborn infants on cerebral vascular resistance, cerebral blood flow, and cerebral oxygen consumption in hypotensive newborn pigs.

\section{METHODS}

Animal preparations. Surgical and experimental procedures employed were reviewed and approved by the Animal Care and Use Committee at the University of Tennessee, Memphis, TN.

Newborn pigs (1-2 kg) were instrumented prior to $36 \mathrm{~h}$ of age. Surgery was performed under aseptic conditions. Piglets were anesthetized with a mixture of halothane, nitrous oxide, and oxygen. Polyurethane catheters were placed in the descending aorta (via an umbilical artery) for blood sampling and reference withdrawal in microsphere experiments, and in the left ventricle (via the right carotid artery) for microsphere injections. In piglets, ligation of one carotid artery has no detectable effect on cerebral blood flow $(3,8)$. Unlike in most animals, ligation of a femoral or brachial artery in a piglet results in dysfunction of the dependent limb. The trachea was exposed and the muscles sutured together dorsal to it to create a tracheal loop directly below the incision. This procedure allowed exposure of the trachea when the skin sutures were removed so that tracheal cannulation could be performed without general anesthesia on the day of the experiment.

Following surgery, the piglets were given benzathene penicillin, gentamicin, and colloidal iron and placed in cages warmed by overhead lamps. They were provided a continual supply of pig milk substitute and water. Experimentation was performed on the third postoperative day. On the morning of experimentation, the skin on the neck was anesthetized with lidocaine, the sutures removed, and the skin retracted slightly to expose the trachea. Following tracheal cannulation, the piglet was mechanically ventilated (peak tracheal pressure, $10 \mathrm{~cm}$ water) at a rate at which voluntary breathing stopped using a Baby Bird ventilator. The midline of the scalp was anesthetized with lidocaine and a 2-cm incision made to expose the cranial suture. The sagittal sinus was cannulated with a 22-gauge Angiocath for collection of cerebral venous blood. The Angiocath was secured with Superglue. The piglet was warmed with an overhead lamp. The piglet was allowed to rest in the sling for approximately $30 \mathrm{~min}$, and then radioactive microsphere determinations of cerebral blood flow and cardiac output were made and blood samples were drawn from the aorta and sagittal sinus. Thirty $\mathrm{ml} / \mathrm{kg}$ of blood were withdrawn from the aorta over a 10-min period and a second microsphere injection and sample collection made 10 min later. Indomethacin trihydrate $(0.2 \mathrm{mg} / \mathrm{kg})$ was administered intraarterially and fur- 
ther microsphere blood flow determinations and blood samplings were made 20 and $40 \mathrm{~min}$ later. Vehicle control animals received saline injections instead of saline-containing indomethacin trihydrate.

Blood chemistry determinations and cerebral $\mathrm{O}_{2}$ consumption. Blood $\mathrm{pH}, \mathrm{PCO}_{2}$, and $\mathrm{PO}_{2}$ were determined using an Instrumentation Laboratories Blood Gas Analyzer. Percent saturation of the hemoglobin in the arterial and sagittal sinus blood were determined using an American Optical Reflection Oxymeter. Blood hemoglobin was determined using a Reichert Hemoglobinometer. We assumed the oxygen capacity of the hemoglobin to be $1.39 \mathrm{ml}$ of $\mathrm{O}_{2} / \mathrm{g}$ of hemoglobin. Blood oxygen content was then calculated as: $\mathrm{C}_{\mathrm{O}_{2}}=(\mathrm{g}$ hemoglobin $/ \mathrm{ml} \times 1.39 \mathrm{ml} \mathrm{O} / \mathrm{g}$ hemoglobin $\times \%$ saturation of hemoglobin with $\left.\mathrm{O}_{2}\right)+$ dissolved $\mathrm{O}_{2}$. Cerebral metabolic rate for oxygen was calculated as (arterial $\mathrm{C}_{\mathrm{O}_{2}}$ - venous $\left.\mathrm{C}_{\mathrm{O}_{2}}\right) \times$ cerebral blood flow.

Radioactive microsphere determination of cerebral blood flow. A known amount of radioactivity as ${ }^{57} \mathrm{Co},{ }^{113} \mathrm{Sn},{ }^{103} \mathrm{Ru},{ }^{95} \mathrm{Nb}$, or ${ }^{46} \mathrm{Sc}$ in $15 \mu \mathrm{m}$ microspheres $(300,000-800,000$ microspheres in $0.2 \mathrm{ml}$ saline) was injected into the left ventricle and the injection line flushed with $1 \mathrm{ml}$ saline. Withdrawal of reference blood samples $(1.03 \mathrm{ml} / \mathrm{min}$ from the descending aorta) was begun 15 $\mathrm{s}$ prior to microsphere injections and continued for $2 \mathrm{~min}$ after the injection. Blood withdrawn for the initial blood flow determination began the hemorrhage period. Thereafter, withdrawn blood was replaced with blood removed when the piglet was hemorrhaged. Following the experiment, the piglet was killed by injecting euthanasia solution (T-61) into the left ventricle, and the brain was removed. The brain was subdivided into major regions and tissues. Samples were counted in a well-type $\gamma$ counter. The energy from each nuclide was separated by differential spectroscopy. Aliquots of the actual microsphere solutions injected were used for overlap calculations. The lungs were counted to detect extensive arteriovenous shunting of microspheres. "Lung blood flow" (comprised of bronchial flow and whole body arteriovenous shunt flow) has averaged $2 \%$ of cardiac output, indicating that no extraordinary shunting of microspheres occurs. Cardiac output was calculated as cardiac output $=($ reference withdrawal rate $) \times($ counts injected $) \times($ counts in reference withdrawal) ${ }^{-1}$. Blood flow to each brain region at the time the microspheres were injected was calculated by using the formula: $\mathrm{Q}=\mathrm{C} \times \mathrm{R} \times \mathrm{CR}^{-1}$, where $\mathrm{Q}=$ organ blood flow in $\mathrm{ml} / \mathrm{min} \times 100 \mathrm{~g}, \mathrm{C}=$ counts per $100 \mathrm{~g}$ tissue, $\mathrm{R}=$ rate of withdrawal of reference blood sample in $\mathrm{ml} / \mathrm{min}$, and $\mathrm{CR}=$ total counts in reference arterial blood sample. Cerebral vascular resistance was calculated by dividing mean arterial pressure by cerebral blood flow. We assumed cerebral venous pressure to be negligible because we measured sagittal sinus pressure in several piglets and found it to be less than $5 \mathrm{~mm} \mathrm{Hg}$ and relatively constant over time.

Prostanoid analysis. 6-Keto-PGF ${ }_{1 \alpha}$ in plasma was determined by radioimmunoassay as described previously $(2,3)$. All tubes contained an identical amount of pig plasma. The standard curves, knowns, blanks, and make-up for greater dilutions used plasma from the same piglet as the unknowns, following dialysis of the plasma against 4 liters of Krebs bicarbonate buffer.

Antisera used were produced in rabbits immunized with 6keto-PGF ${ }_{1 \alpha}$ coupled to thyroglobulin using the mixed anhydride method. Cross-reactivities of the antibody with other known, biologically relevant prostanoids, leukotrienes, and arachidonic acid were all below $1 \%$. The assays were performed in gelatinTris buffer using tritiated 6-keto-PGF ${ }_{1 \alpha}$. Following 24-h incubation at $4^{\circ} \mathrm{C}$, the free fraction was separated from the fraction bound to antibody by precipitating the rabbit antibodies with antirabbit $\gamma$ globulin and $60 \%$ saturated ammonium sulfate solution. Data were handled by computer, with determination of second-order regression of free tracer over tracer bound to antibody against unlabeled 6-keto-PGF ${ }_{1 \alpha}$ by the method of least squares. All unknowns were assayed at three dilutions with parallelism between the unknown dilution curve and the standard curve required before using the results.

Statistical analysis. All values are presented as means \pm SEM. Comparisons between two values were made using $t$ tests (for paired or unpaired observations, as appropriate), and comparisons among three or more values were made using analysis of variance, followed by pair-wise tests when appropriate. Significance at the $95 \%$ confidence level was required for inference that populations were different.

Table 1. Arterial pressure, cardiac output, blood gases, and pH of unanesthetized newborn pigs

\begin{tabular}{|c|c|c|c|c|c|}
\hline \multirow[b]{3}{*}{ Time (min) } & & \multicolumn{4}{|c|}{ Vehicle $(n=7)$} \\
\hline & & \multicolumn{2}{|c|}{ Hemorrhage* } & \multicolumn{2}{|c|}{ Vehicle } \\
\hline & & 0 & 20 & 40 & 60 \\
\hline Arterial pressure $(\mathrm{mm} \mathrm{Hg})$ & $\cdot$ & $60 \pm 6$ & $35 \pm 3 \uparrow$ & $36 \pm 2 \uparrow$ & $33 \pm 2 \uparrow$ \\
\hline Cardiac output & & $404 \pm 106$ & $256 \pm 77 \dagger$ & $256 \pm 44 \dagger$ & $290 \pm 13 \dagger$ \\
\hline \multicolumn{6}{|l|}{ Arterial blood } \\
\hline $\mathrm{pH}$ & & $7.47 \pm 0.03$ & $7.44 \pm 0.03$ & $7.36 \pm 0.04$ & $7.36 \pm 0.07$ \\
\hline $\mathrm{PO}_{2}(\mathrm{~mm} \mathrm{Hg})$ & & $70 \pm 5$ & $73 \pm 5$ & $75 \pm 4$ & $78 \pm 4$ \\
\hline $\mathrm{PCO}_{2}(\mathrm{~mm} \mathrm{Hg})$ & & $30 \pm 1$ & $23 \pm 1 \dagger$ & $24 \pm 2 \dagger$ & $23 \pm 2 \dagger$ \\
\hline \multirow[t]{3}{*}{ Hemoglobin $(\mathrm{g} / 100 \mathrm{ml})$} & & $8.5 \pm 0.3$ & $6.7 \pm 0.3 \dagger$ & $5.7 \pm 0.3 \dagger$ & $5.8 \pm 0.4 \dagger$ \\
\hline & & \multicolumn{4}{|c|}{ Indomethacin $(n=6)$} \\
\hline & & \multicolumn{2}{|c|}{ Hemorrhage* } & \multicolumn{2}{|c|}{ Indomethacin } \\
\hline Time $(\min )$ & & 0 & 20 & 40 & 60 \\
\hline Arterial pressure $(\mathrm{mm} \mathrm{Hg})$ & & $59 \pm 4$ & $40 \pm 4 \dagger$ & $43 \pm 4 \dagger$ & $35 \pm 2 \dagger$ \\
\hline Cardiac output & & $474 \pm 86$ & $239 \pm 32 \dagger$ & $240 \pm 11 \dagger$ & $230 \pm 69 \dagger$ \\
\hline \multicolumn{6}{|l|}{ Arterial blood } \\
\hline $\mathrm{pH}$ & & $7.42 \pm 0.02$ & $7.47 \pm 0.05$ & $7.36 \pm 0.05$ & $7.38 \pm 0.04$ \\
\hline $\mathrm{PO}_{2}(\mathrm{~mm} \mathrm{Hg})$ & & $70 \pm 4$ & $87 \pm 3 \dagger$ & $85 \pm 3 \dagger$ & $84 \pm 3 \uparrow$ \\
\hline $\mathrm{PCO}_{2}(\mathrm{~mm} \mathrm{Hg})$ & & $35 \pm 2$ & $27 \pm 2 \dagger$ & $25 \pm 1 \dagger$ & $25 \pm 1 \dagger$ \\
\hline Hemoglobin $(\mathrm{g} / 100 \mathrm{ml})$ & & $9.5 \pm 0.6$ & $7.3 \pm 0.3 \dagger$ & $6.4 \pm 0.4 \dagger$ & $6.1 \pm 0.4 \dagger$ \\
\hline
\end{tabular}

$* 30 \mathrm{ml} / \mathrm{kg}$.

$\dagger p<0.05$ compared to 0 min (prehemorrhage).

$\ddagger 0.2 \mathrm{mg} / \mathrm{kg}$, intraarterial. 


\section{RESULTS}

Table 1 shows the effect of the hemorrhage of $30 \mathrm{ml} / \mathrm{kg}$ on the arterial pressure, cardiac output, and arterial blood gases and $\mathrm{pH}$ of the piglets in the two groups. The hemorrhage decreased arterial pressure, cardiac output, arterial $\mathrm{PCO}_{2}$, arterial $\mathrm{pH}$, and arterial hemoglobin concentration. Neither vehicle nor indomethacin affected arterial pressure, cardiac output, or arterial blood gases, $\mathrm{pH}$, or hemoglobin concentration.

Aortic and sagittal sinus 6-keto-PGF ${ }_{1 \kappa}$ concentrations 20 and $60 \mathrm{~min}$ following the hemorrhage are shown in Table 2. Either vehicle or indomethacin $(0.2 \mathrm{mg} / \mathrm{kg})$ were administered immediately after the 20 -min hemorrhage samples were drawn. The indomethacin treatment significantly decreased the concentration of 6-keto-PGF in $_{1 \alpha}$ in both aortic plasma and sagittal sinus plasma. Further, indomethacin at $0.2 \mathrm{mg} / \mathrm{kg}$ inhibited net cerebral vascular prostacyclin production. Thus, in the vehicletreated animals, net cerebral vascular prostacyclin production increased from $4.9 \pm 1.9$ to $14.0 \pm 5.4 \mathrm{ng} / 100 \mathrm{~g} \cdot$ min between 20 and 60 min following hemorrhage $(n=5)$. In contrast, when indomethacin was administered after the 20-min sample, the net cerebral vascular prostacyclin production decreased from $4.8 \pm$ 1.9 to $2.3 \pm 0.5 \mathrm{ng} / 100 \mathrm{~g} \cdot \min (n=5)$.

Hemorrhagic hypotension caused a decrease in cerebral vascular resistance $20 \mathrm{~min}$ following the hemorrhage (Fig. 1). Vehicle administration 20 min after the hemorrhage did not affect cerebral vascular resistance, which appeared to fall farther 40 and $60 \mathrm{~min}$ following the hemorrhage, although these values were not significantly different from the 20 -min value. In contrast, the cerebral vascular resistances of piglets treated with indomethacin $20 \mathrm{~min}$ after hemorrhage were significantly elevated at 40 and $60 \mathrm{~min}$ when compared to those treated with vehicle.

Table 2. Plasma 6-keto-PGF $F_{1 \alpha}$ concentrations in unanesthetized, hypotensive newborn pigs

\begin{tabular}{llc}
\hline & \multicolumn{2}{c}{ 6-keto- $\mathrm{PGF}_{1 \alpha}(\mathrm{pg} / \mathrm{ml})$} \\
\cline { 2 - 3 } & $20 \mathrm{~min} *$ & $60 \mathrm{~min} *$ \\
\hline Vehicle & & \\
$\quad$ Aorta $(n=5)$ & $292 \pm 94$ & $255 \pm 75$ \\
$\quad$ Sagittal sinus $(n=5)$ & $392 \pm 113$ & $534 \pm 90$ \\
Indomethacint & & \\
$\quad$ Aorta $(n=5)$ & $219 \pm 58$ & $68 \pm 5 \$$ \\
$\quad$ Sagittal sinus $(n=5)$ & $278 \pm 54$ & $137 \pm 14 \ddagger$ \\
\hline
\end{tabular}

* Time after hemorrhage $(30 \mathrm{ml} / \mathrm{kg})$.

$\dagger 0.2 \mathrm{mg} / \mathrm{kg}$, intraarterial between 20 and $60 \mathrm{~min}$.

$\ddagger p<0.05$ compared to vehicle.

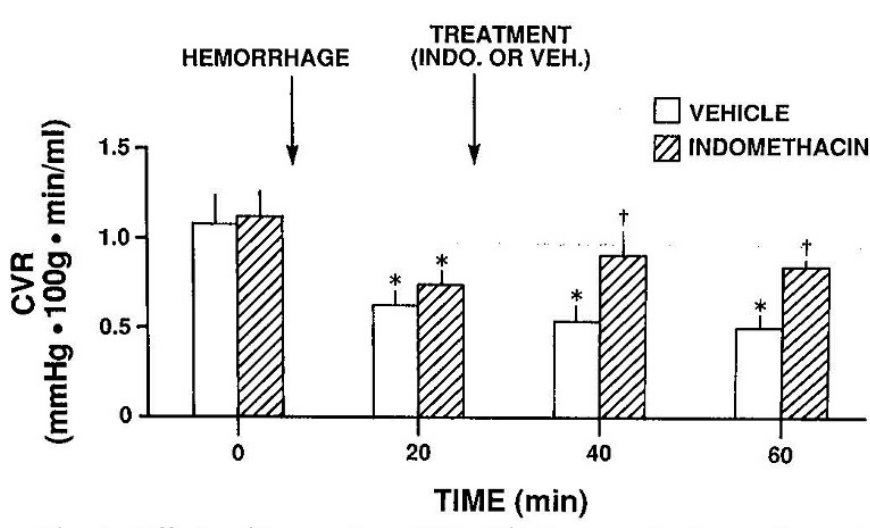

Fig. 1. Effects of hemorrhage $(30 \mathrm{ml} / \mathrm{kg})$ on cerebral vascular resistances $(C V R)$ of newborn pigs. Indomethacin $(0.2 \mathrm{mg} / \mathrm{kg}$, intraarterial) $(n=6)$ or vehicle $(n=7)$ was administered where indicated. ${ }^{*} p<0.05$ compared to prehemorrhage. $\dagger p<0.05$ compared to vehicle.
The decrease in cerebral vascular resistance induced by hemorrhagic hypotension was sufficient to allow maintenance of cerebral blood flow not different from control at 20,40 , and 60 min following the hemorrhage (Fig. 2). Treatment with indomethacin $(0.2 \mathrm{mg} / \mathrm{kg})$ after $20 \mathrm{~min}$ of hemorrhage caused an overall decrease in cerebral blood flow of about $24 \pm 7 \% 40 \mathrm{~min}$ later, which was most pronounced in the cerebral gray matter, pons, and brainstem. Effects on flow to the diencephalon, mesencephalon, and medulla were minimal.

Cerebral oxygen consumption also was maintained well after the hemorrhage (Fig. 3). Vehicle treatment $20 \mathrm{~min}$ after the hemorrhage had no effect on cerebral oxygen consumption. In contrast, treatment with $0.2 \mathrm{mg} / \mathrm{kg}$ of indomethacin $20 \mathrm{~min}$ after hemorrhage produced a significant decrease in cerebral oxygen consumption 40 min later. However, all the piglets in the present study, whether treated with vehicle or indomethacin, could be awakened easily at the end of the protocol. Therefore, the cerebral oxygen consumption in the hemorrhaged pigs treated with 0.2 $\mathrm{mg} / \mathrm{kg}$ of indomethacin, while significantly decreased in comparison to the value prior to treatment with indomethacin or in comparison to that in the vehicle-treated animals, was sufficient to maintain consciousness.

\section{DISCUSSION}

The present investigation indicates that treatment of unanesthetized hypotensive newborn pigs with $0.2 \mathrm{mg} / \mathrm{kg}$ of indomethacin increases the cerebral vascular resistance to a level approaching the normotensive level, thereby decreasing cerebral blood flow $20-30 \%$. Cerebral oxygen consumption declines similarly and in parallel with cerebral blood flow following treatment of hypotensive newborn piglets with $0.2 \mathrm{mg} / \mathrm{kg}$ of indomethacin.

A study in normotensive fetal lambs demonstrated that the decreases in cerebral blood flow caused by indomethacin treatment are not secondary to decreases in cerebral metabolism (9). Fifteen $+3 \mathrm{mg} / \mathrm{kg} \cdot \mathrm{h}$ did not alter cerebral oxygen consumption but decreased blood flow to cerebral hemispheres $23 \pm 6 \%$. Therefore, it appears that the decrease in cerebral oxygen consumption observed in the present experiment is due to the decrease in cerebral blood flow rather than the converse.

Previously, using an identical protocol, we found that treatment of hypotensive newborn piglets with $5 \mathrm{mg} / \mathrm{kg}$ of indomethacin caused an increase in cerebral vascular resistance of $180 \%$ $40 \mathrm{~min}$ after treatment (5) in comparison to the increase of approximately $13 \%$ observed following treatment with $0.2 \mathrm{mg} /$ $\mathrm{kg}$ of indomethacin. As a result of the large increase in cerebral vascular resistance $40 \mathrm{~min}$ following treatment with $5 \mathrm{mg} / \mathrm{kg}$ of indomethacin in hypotensive pigs, cerebral blood flow had fallen to $24 \pm 4 \mathrm{ml} / 100 \mathrm{~g} \cdot \mathrm{min}$ and cerebral oxygen consumption fell to $1.1 \pm 0.3 \mathrm{ml} / 100 \mathrm{~g} \cdot \mathrm{min}$. Seventy-five percent of the hypotensive piglets treated with $5 \mathrm{mg} / \mathrm{kg}$ of indomethacin became comatose by $40 \mathrm{~min}$ after treatment with a mean cerebral $\mathrm{O}_{2}$ consumption of only $0.4 \mathrm{ml} / 100 \mathrm{~g} \cdot \mathrm{min}$. All of the piglets treated with $0.2 \mathrm{mg} / \mathrm{kg}$ of indomethacin were conscious $40 \mathrm{~min}$ following the treatment, with mean cerebral blood flow nearly double that of the piglets treated with the higher dose of indomethacin. The cerebral oxygen consumption of hypotensive piglets treated with the lower dose of indomethacin was about five times greater than that of the comatose piglets.

It should be noted that large decreases in cerebral blood flow upon treatment with $5 \mathrm{mg} / \mathrm{kg}$ of indomethacin are observed in hypotensive (5) or asphyxiated piglets, but not in normotensive piglets with normal blood gases (3). The effects of $0.2 \mathrm{mg} / \mathrm{kg}$ of indomethacin on cerebral blood flow of normotensive piglets has not been examined, but we expect the effect to be even less than when the higher dose is used.

Interestingly, the effects of 0.2 and $5 \mathrm{mg} / \mathrm{kg}$ of indomethacin on net cerebral prostanoid production on the vascular side of the blood brain barrier were quite similar ( 5 , present study). In both cases, the large increase in net cerebral vascular prostacyclin 

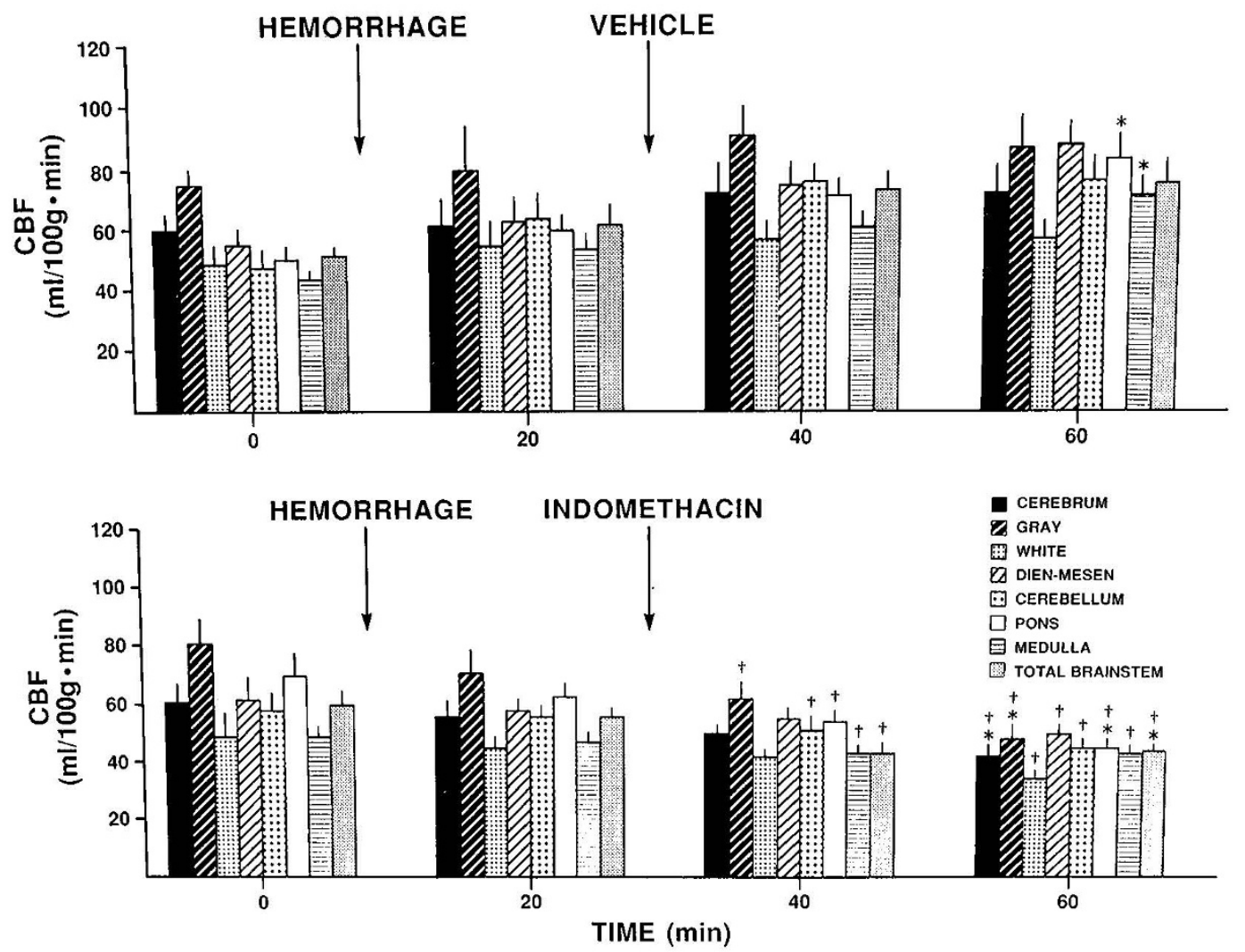

Fig. 2. Effect of hemorrhage $(30 \mathrm{ml} / \mathrm{kg})$ on cerebral blood flow (CBF) of newborn pigs. Indomethacin $(0.2 \mathrm{mg} / \mathrm{kg}$, intraarterial) $(n=6)$ or vehicle $(n=7)$ was administered where indicated. ${ }^{*} p<0.05$ compared to $20 \mathrm{~min}$ (posthemorrhage). $\dagger p<0.05$ compared to vehicle.

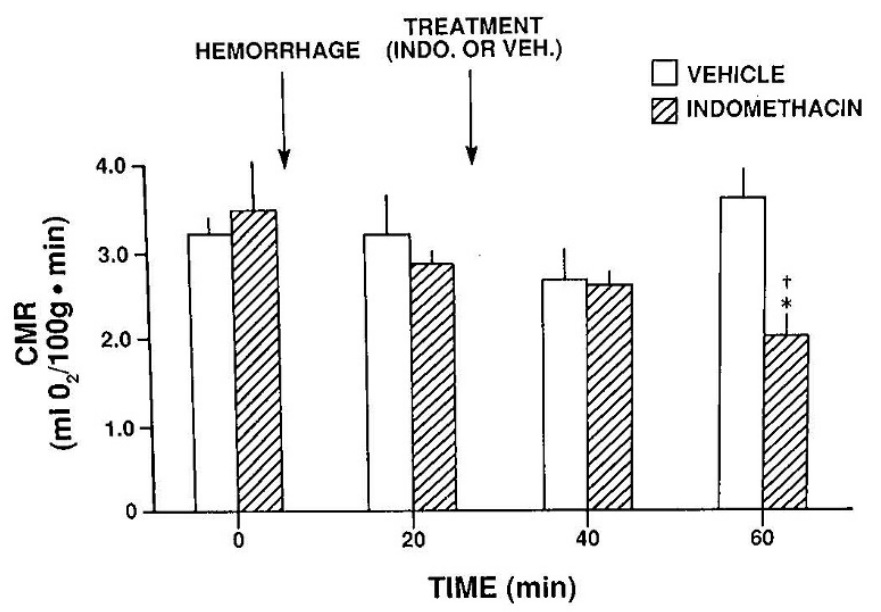

Fig. 3. Effect of hemorrhage $(30 \mathrm{ml} / \mathrm{kg})$ on cerebral oxygen consumption of newborn pigs. Indomethacin $(0.2 \mathrm{mg} / \mathrm{kg}$, intraarterial $)(n=$ $6)$ or vehicle $(n=7)$ was administered where indicated. ${ }^{*} p<0.05$ compared to $20 \mathrm{~min}$ (post hemorrhage). $\dagger p<0.05$ compared to vehicle.

production observed at $60 \mathrm{~min}$ following hemorrhage was abolished. It is noteworthy that no increase in net cerebral vascular prostacyclin production was observed 20 min following hemorrhage, even though cerebral vascular resistance had fallen. In contrast, very large increases in concentrations of both 6-keto$\mathrm{PGF}_{1 \kappa}$ and $\mathrm{PGE}_{2}$ in cortical subarachnoid cerebrospinal fluid are observed within 20 min following hemorrhage, coincident with the decrease in cerebral vascular resistance (10). We speculate that, at a dose of $0.2 \mathrm{mg} / \mathrm{kg}$, insufficient indomethacin crosses the blood-brain barrier to inhibit the cerebral prostanoid production markedly. As a result, sufficient cerebral prostanoid produc- tion continues to aid in maintenance of cerebral blood flow following hemorrhage. Suggestive evidence that indomethacin does not freely cross the blood-brain barrier is obtained from studies of effects of 2 and $10 \mathrm{mg} / \mathrm{kg}$ of intravenous indomethacin, on conversion of topical arachidonic acid to prostanoids on the pial surface (1). Two $\mathrm{mg} / \mathrm{kg}$ of indomethacin was less effective than $10 \mathrm{mg} / \mathrm{kg}$ of indomethacin in inhibiting this conversion. Thus, it appears that vasodilator prostanoids produced on the brain side of the blood-brain barrier (nervous tissue, smooth muscle, etc.) may be more important in the maintenance of cerebral blood flow following hypotension in newborn pigs than vascular luminal production.

The possibility that cyclooxygenase inhibition could decrease the incidence of intraventricular hemorrhage in the premature newborn is currently being investigated. Studies conducted by Ment et al. $(11,12)$ using a beagle puppy model of intraventricular hemorrhage suggests that indomethacin may protect against intraventricular hemorrhage in the puppy model and that 0.3 $\mathrm{mg} / \mathrm{kg}$ may be effective. In addition, randomized indomethacin trials to determine if treatment with indomethacin is effective in preventing intraventricular hemorrhage have produced data that suggest that early treatment with indomethacin in very low birth weight infants may decrease not only the overall incidence of intraventricular hemorrhage but also the severity of hemorrhage $(6,7)$. These studies in premature babies use $0.2 \mathrm{mg} / \mathrm{kg}$ of indomethacin followed by $0.1 \mathrm{mg} / \mathrm{kg}$ at 12 -h intervals, as it is typically used for closure of patent ductus arteriosis.

The present study indicates that $0.2 \mathrm{mg} / \mathrm{kg}$ of indomethacin increases cerebral vascular resistance, thereby decreasing cerebral blood flow and cerebral oxygen consumption modestly in hypotensive newborn pigs. However, the catastrophic effects of 5 $\mathrm{mg} / \mathrm{kg}$ of indomethacin on the hypotensive piglet are not observed with the dose of $0.2 \mathrm{mg} / \mathrm{kg}$, and the piglets remain conscious at blood pressures as low as $35 \mathrm{~mm} \mathrm{Hg}$. The effects of such treatment on cerebral hemodynamics at arterial pressures 
below the autoregulatory range and on cerebral hemodynamics of postasphyxia neonates with compromised cerebral circulatory control remain to be determined.

\section{REFERENCES}

1. Leffler CW. Busija DW 1985 Arachidonate metabolism on the cerebral surface of newborn pigs. Prostaglandins 30:811-818

2. Leffler CW, Busija DW 1985 Prostanoids in cortical subarachnoid cerebrospinal fluid and pial arterial diameter in newborn pigs. Circ Res 57:689-694

3. Leffler CW. Busija DW, Fletcher AM, Beasley DG, Hessler JR. Green RS 1985 Effects of indomethacin upon cerebral hemodynamics of newborn pigs. Pediatr Res 19:1160-1164

4. Leffler CW, Busija DW. Beasley DG. Fletcher AM, Green RS 1986 Effects of indomethacin on cardiac output distribution in normal and asphyxiated piglets. Prostaglandins 31:183-190

5. Lefler CW, Busija DW, Beasley DG. Fletcher AM Maintenance of cerebra circulation during hemorrhagic hypotension in newborn pigs: role of prostanoids. Circ Res (in press)
6. Ment LR, Duncan CC, Ehrenkranz RA, Kleinman CS, Pitt BR, Taylor KJW, Scott DT, Stewart WB, Gettner P 1985 Randomized indomethacin trial for prevention of intraventricular hemorrhage in very low birth weight infants. J Pediatr 107:937-943

7. Setzer ES, Morse BM, Goldberg RN, Smith M, Bancalari E 1984 Prophylactic indomethacin and intraventricular hemorrhage (IVH) in the premature. Pediatr Res 18:345A(abstr)

8. Laptook AK, Stonestreet BS, Oh W 1983 The effect of carotid artery ligation on brain blood flow in newborn piglets. Brain Res 276:51-59

9. Hohimer AR, Richardson BS, Bissonnette JM, Machida CM 1985 The effect of indomethacin on breathing movements and cerebral blood flow and metabolism in the fetal sheep. J Dev Physiol 7:217-228

10. Leffler CW, Busija DW Prostanoids and pial arteriolar diameter in hypotensive newborn pigs. Am J Physiol (in press)

11. Ment LR, Stewart WB, Duncan CC, Scott DT, Lambrecht R 1983 Beagie puppy model of intraventricular hemorrhage: effect of indomethacin on cerebral blood flow. J Neursurg 58:857-862

12. Ment LR, Stewart WB, Scott DT, Duncan CC 1983 Beagle puppy model of intraventricular hemorrhage: randomized indomethacin prevention trial. Neurology 33:179-184 